\title{
Factors affecting sphincter-preserving resection treatment for patients with low rectal cancer
}

\author{
ZHENQIANG SUN $^{1,2}$, XIANBO YU ${ }^{1}$, HAIJIANG WANG ${ }^{1}$, MING MA $^{3}$, ZELIANG ZHAO $^{1}$ and QISAN WANG ${ }^{1}$ \\ ${ }^{1}$ Department of Gastrointestinal Surgery, Affiliated Tumor Hospital, Xinjiang Medical University, Ürümqi, Xinjiang 830011; \\ ${ }^{2}$ Research Laboratory of Disease Genomics, Cancer Research Institute, Central South University, Changsha, Hunan 410078; \\ ${ }^{3}$ Department of Hepatobiliary Surgery, Xinjiang Uygur Autonomous Region People's Hospital, \\ Ürümqi, Xinjiang 830001, P.R. China
}

Received July 6, 2014; Accepted March 17, 2015

DOI: $10.3892 /$ etm.2015.2552

\begin{abstract}
The aim of the present study was to identify the factors associated with the use of sphincter-preserving resection (SPR) surgery for the treatment of low rectal cancer. A total of 330 patients with histopathologically confirmed low rectal cancer were divided into two groups, namely the abdominoperineal resection (APR) and sphincter-preserving (SP) groups. For SPR factor analysis, the $\chi^{2}$ test was performed as the univariate analysis, while a logistic regression test was conducted as the multivariate analysis. Of the 330 patients, 192 cases $(58.18 \%)$ received SPR surgery and 138 cases $(41.82 \%)$ underwent an APR. Univariate analysis results revealed that the sphincter-preserving factor was significantly associated with age, gender, ethnicity, body mass index (BMI), total infiltrated circumference, distance of the tumor from the anal verge (DTAV), depth of invasion and tumor grade $(\mathrm{P}<0.05)$. However, there were no statistically significant associations with family medical history, diabetes history, venous tumor embolism, growth type, tumor length, lymphatic metastasis and level of preoperative carcinoembryonic antigen $(\mathrm{P}>0.05)$. Multivariate analysis indicated that the sphincter-preserving factor was strongly associated with DTAV and the depth of invasion, with significant statistical difference $(\mathrm{P}<0.05)$. Therefore, selecting SPR surgery for patients with low rectal cancer is dependent on age, gender, ethnicity, BMI, the total infiltrated circumference, DTAV, depth of invasion and tumor grade. In addition, DTAV and the depth of invasion are independent risk factors for the selection of SPR surgery.
\end{abstract}

Correspondence to: Professor Haijiang Wang, Department of Gastrointestinal Surgery, Affiliated Tumor Hospital, Xinjiang Medical University, 789 Suzhou East Street, Ürümqi, Xinjiang 830011, P.R. China

E-mail: medicine120@163.com

Key words: low rectal cancer, abdominoperineal resection, sphincter-preserving, clinicopathological features

\section{Introduction}

With improvements in living standards, colorectal cancer has become one of the most common malignant tumors worldwide. In China the morbidity of rectal cancer is 24 individuals per hundred thousand and it rose by $4 \%$ in the past decade. It also ranks third amongst the other cancers in morbidity. The incidence rate of rectal cancer, and particularly low rectal cancer, has increased, accounting for $60-75 \%$ (1). Abdominoperineal resection (APR) has remained the standard surgical procedure for the treatment of low rectal cancer (2). However, certain patients are unable to undergo APR treatment due to their inability to tolerate the lower quality of life caused by the permanent anal rechanneling following the procedure. Through carrying out preoperative neoadjuvant chemotherapy and with the development of surgical techniques, it is now possible to perform sphincter-preserving resection (SPR) on cases of low and ultra-low rectal cancer $(3,4)$. SPR can improve postoperative quality of life, and there is no difference compared with APR treatment in terms of the degree of radical surgery required (5). Therefore, to a certain extent, SPR has replaced APR in becoming the first choice treatment for cases of low rectal cancer (6). However, the decision with regard to the selection of APR or SPR surgery for treatment remains controversial. Thus, the aim of the present study was to investigate the associated factors of selecting SPR surgery for the treatment of low rectal cancer. As it is known, the radical resection treatment of high and midrectal cancers has been standardized. Both of these methods are performed by receiving sphincter preservation surgery, in which the former ones can be treated by partial mesorectal excision and the later by total mesorectal resection $(7,8)$. However, for surgical therapy the low rectal cancer remains controversial. In the past, some patients receive APR as the standard surgical procedure (9) whereas others benefit from sphincter preservation (2).

\section{Materials and methods}

Patients and clinicopathological parameters. Between June 2006 and December 2009, a total of 330 patients, admitted to the Affiliated Tumor Hospital of Xinjiang 
Medical University (Ürümqi, China) with histopathologically-confirmed low rectal cancer, were enrolled in the study. Rectal cancer with a distance of the tumor from the anal verge (DTAV) of 3-7 cm was defined as low rectal cancer (10). All patients received radical surgery. Clinicopathological features, including age, gender, ethnicity, body mass index (BMI), history of diabetes, family medical history, level of preoperative carcinoembryonic antigen (CEA), total infiltrated circumference, DTAV, depth of invasion, tumor grade, venous tumor embolism, growth type, tumor length and lymphatic metastasis were fully reviewed. The tumornode-metastasis (TNM) stage was determined according to the American Joint Committee on Cancer/International Union Against Cancer TNM staging system of colorectal cancer (11). The following criteria were used to exclude patients: Preoperative adjuvant chemotherapy (18 cases), preoperative radiotherapy ( 8 cases), preoperative chemoradiotherapy (59 cases), confirmed metastasis (63 cases) and rejection of APR treatment (13 cases). The study was approved by the Medical Ethics Committee of the Affiliated Tumor Hospital of Xinjiang Medical University (no. W201324). Informed consent was obtained from all the patients prior to their participation in the study.

Surgical pattern. Open surgery using the total mesorectal excision (TME) (12) technique was successfully performed on all 330 patients. Of these, 192 cases (58.18\%) received SPR and 138 cases $(41.82 \%)$ underwent APR. All postoperative incisal margins were pathologically confirmed as negative.

Postoperative therapy. Radiotherapy was applied to all the patients with rectal cancer of $\mathrm{pT}_{3} \mathrm{~N}_{0} \mathrm{M}_{0}$ or $\mathrm{pT}_{1-3} \mathrm{~N}_{1-2} \mathrm{M}_{\mathrm{x}}$. The chemotherapy scheme of FOLFOX6 was administered intravenously injected with intravenously infused $130 \mathrm{mg} / \mathrm{m}^{2}$ oxaliplatin (L-OHP) that lasted $3 \mathrm{~h}$ on the first day, an intravenously infused $300 \mathrm{mg} / \mathrm{m}^{2}$ calcium folinate $(\mathrm{CF})$ injection, an intravenously injected $400 \mathrm{mg} / \mathrm{m}^{2} 5$-FU injection and a $2,400 \mathrm{mg} / \mathrm{m}^{2} 5$-FU continuous intravenous infusion by a micropump for $48 \mathrm{~h}$, for 14 days per cycle and for 12 cycles in total. For the recurrence therapy, the scheme of FOLFIRI was performed at 2 weeks per therapeutic circle until the dose became intolerable or invalid. This was performed on the first day with an intravenously infused $350 \mathrm{mg} / \mathrm{m}^{2}$ Irinotecan (CPT-11) injection, an intravenously infused $300 \mathrm{mg} / \mathrm{m}^{2} \mathrm{CF}$ injection, a $400 \mathrm{mg} / \mathrm{m}^{2} 5$-FU injection that was intravenously injected and a $2,400 \mathrm{mg} / \mathrm{m}^{2}$ 5-FU continuous intravenous infusion by a micropump for $48 \mathrm{~h}$. For the patients who exhibited drug resistance, the chemotherapy scheme of XELOX was used. This therapy consisted of the following on the first day: an intravenously infused $130 \mathrm{mg} / \mathrm{m}^{2} \mathrm{~L}-\mathrm{OHP}$ injection for $3 \mathrm{~h}$, $1,000 \mathrm{mg} / \mathrm{m}^{2}$ capecitabine tablets, po., twice a day, from the first to the fourth day, 3 weeks per cycle and for nine cycles in total. These treatment criteria were according to the Ministry of Health of China (13).

Follow-up assessments. All the patients enrolled in the study were registered at the hospital and complete personal follow-up files of the patients with explicit pathological diagnoses were established. Following surgery, the patients were followed-up once every 3 weeks within the first 6 months, once every 3 months for the subsequent two years and once every 6 months thereafter until they succumbed to the disease or their contact information was lost. Two follow-up procedures were performed, namely outpatient or inpatient review and a telephone follow-up, which included information regarding postoperative chemotherapy, postoperative radiotherapy, chemotherapy regimens, therapeutic course count, side effects, recurrence and survival time. A digital examination was performed each time. Other inspection methods carried out regularly included computerized tomography scans (GE Discovery CT750 HD, GE Healthcare Biosciences, Pittsburgh, PA, USA), magnetic resonance imaging (1.5-T General Electric Medical Systems, Signa ${ }^{\circledR}$, Milwaukee,USA), electronic colonoscopy (PCF-200, Olympus $®$, Tokyo, Japan) and CEA level measurements.

Statistical analysis. Using the SPR procedure as the dependent variable, univariate analysis was performed with the $\chi^{2}$ test and Fisher's exact test. Multivariate correlation analysis was carried out with the logistic regression test. In addition, survival analysis was performed using the log-rank test. All statistical tests were conducted using SPSS 19.0 software (IBM SPSS, Armonk, NY, USA). P $\leq 0.05$ was considered to indicate a statistically significant difference.

\section{Results}

SPR procedure. Of the 192 patients who received SPR surgery, 16 cases underwent a unilateral inguinal lymphadenectomy due to visible lymphadenectasis and nine cases experienced a bilateral inguinal lymphadenectomy. A number of the key steps involved in the SPR surgery are shown in Fig. 1.

Local recurrence results. Of the 330 patients, 192 cases (58.18\%) received an SPR and 138 cases $(41.82 \%)$ underwent APR surgery. In the three-year follow-up period, the total local recurrence rate in the pelvic cavity was $4.24 \%$. The local recurrence rate of the APR group was 3.62\% (5/138), while the rate was 4.69\% (9/192) in the SP group, with no statistically significant difference $(\mathrm{P}>0.05$; Table I).

Univariate correlation analysis for SPR surgery with associated clinicopathological features. For patients with low rectal cancer, the univariate analysis results revealed that the sphincter-preserving factor was associated with age, gender, ethnicity, BMI, total infiltrated circumference, DTAV, depth of invasion and tumor grade, with significant statistical difference $(\mathrm{P}<0.05)$. However, no statistically significant associations were observed with the family medical history, diabetes history, venous tumor embolism, growth type, tumor length, lymphatic metastasis and preoperative CEA level ( $\mathrm{P}>0.05$; Table II).

Multivariate correlation analysis for SPR surgery with associated clinicopathological features. Multivariate correlation analysis indicated that the sphincter-preserving factor was closely associated with DTAV and the depth of invasion, with significant statistical difference $(\mathrm{P}<0.05)$. Consequently, DTAV and the depth of invasion were determined to be independent risk factors for SPR (Table III). 

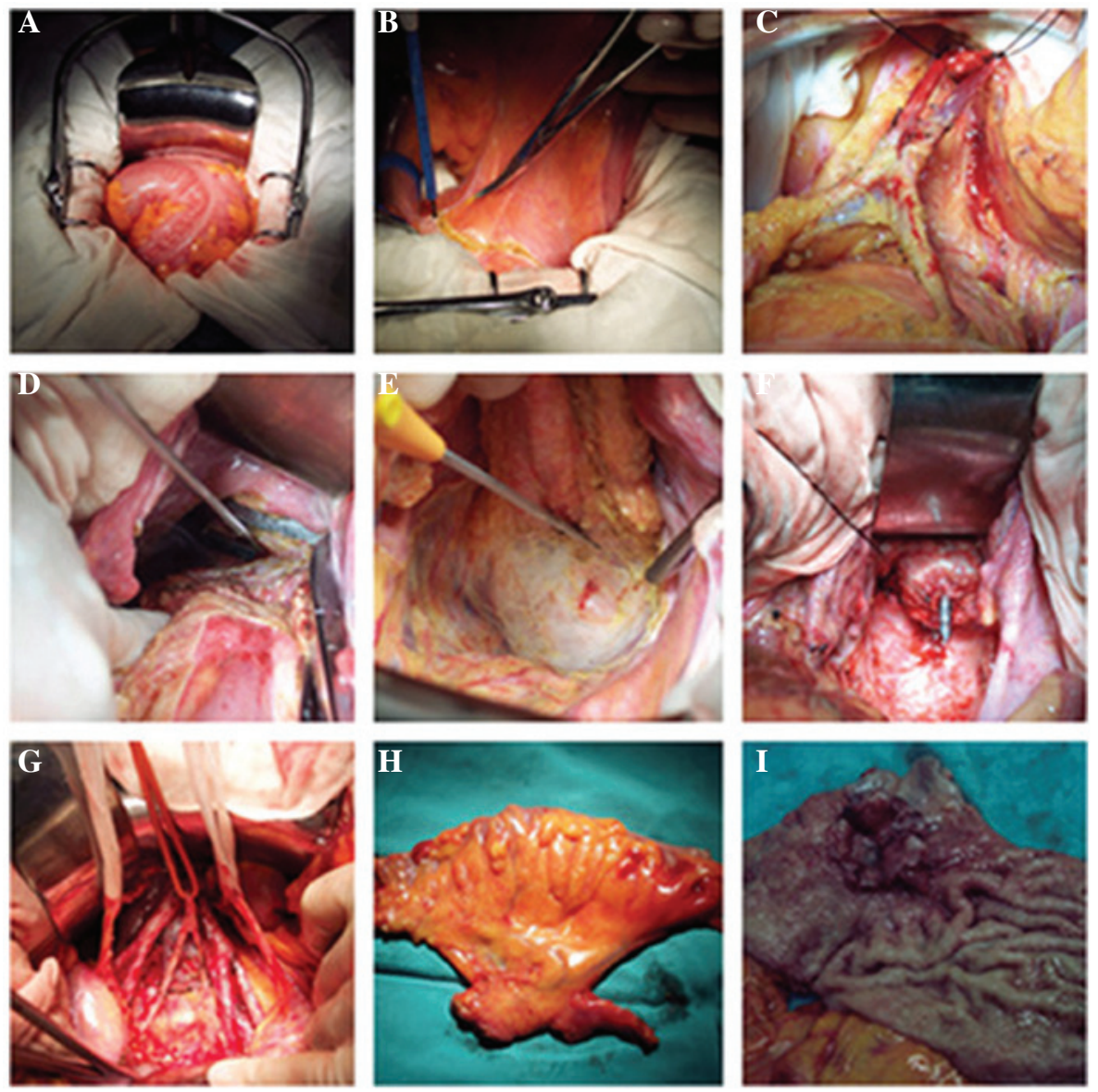

Figure 1. A number of the key procedures included in the sphincter-preserving resection surgery. (A) Abdominal dissection; (B) opening of the mesentery; (C) ligation and incision of the inferior mesenteric artery and vein; (D) separation of the superior rectal spaces; (E) separation of the inferior rectal spaces; (F) insertion and fixation of a tubular anastomat into the distal incisal end of the rectum; (G) bilateral inguinal lymphadenectomy; (H) tissue excision extension and (I) tumor mass.

\section{Discussion}

The TME technique proposed by Heald in 1982 (14) has been regarded as the gold standard for the treatment of rectal cancer. The TME technique significantly decreases the local postoperative recurrence rate of rectal cancer (15). In certain cases, selecting the surgical method is difficult due to the specific tumor location of low rectal cancer. Retaining anal function following radical surgery, local recurrence rate control and improving postoperative quality of life have caused the selection of the appropriate surgical method for the treatment of low rectal cancer to be increasingly studied (16). The local recurrence rate is an important index for evaluating the efficacy of the SPR outcome for low rectal cancer, and this has been extensively studied. In previous studies, Peeters $e t$ al reported a local recurrence rate of $\sim 10 \%$ (17), while You et al reported a local recurrence rate of $6.9 \%$ (18), and in the study by Sun and Wang, a local recurrence rate of $6.71 \%$ was determined (19). In the present study, the local recurrence rate in the pelvic cavity of patients with low rectal cancer was $4.24 \%$, which was 3.62 and $4.69 \%$ in the APR and SP groups, respectively, with no statistically significant difference $(\mathrm{P}>0.05)$. Thus, the SPR surgical method did not increase the local recurrence rate of low rectal cancer. This conclusion is similar to the majority of previous studies $(20,21)$. Consequently, the selec- tion of SPR surgery for the treatment of low rectal cancer primarily depends on the accurate preoperative assessment of the clinicopathological features of the patient, which are beneficial to design a more reasonable surgical scheme.

DTAV is regarded as the most important factor for the determination of anal preserving surgery methods by the majority of researchers $(22,23)$. Colorectal cancer has the particular biological characteristic of upwards growth along the intestinal wall (24). However, the downward growth is generally within $2.0 \mathrm{~cm}$ and growth of $>2.0 \mathrm{~cm}$ presents in only $3 \%$ of cases $(25,26)$. A consensus was recently reached that a distal normal bowel resection of $>2.0 \mathrm{~cm}$ was sufficient for treatment (27). According to the US National Comprehensive Cancer Network guidelines (revised in 2005), resecting a 1-2-cm section of the distal rectal cancer in cases where the DTAV is $<5 \mathrm{~cm}$ is feasible. Based on the characteristics of colorectal cancer anatomy, disconnecting the ligament can extend the intestinal canal by $3-5 \mathrm{~cm}(28)$, which greatly increases the success rate of low anastomosis procedures. At present, according to clinical experience and literature reports $(22,29,30)$, a DTAV of $5 \mathrm{~cm}$ is the boundary for the selection of SPR surgery treatment. Rectal cancer with a DTAV of 5-7 $\mathrm{cm}$ has a relatively high rate of sphincter preservation since the intestinal tube is sufficient in length for convenient anastomosis. In the present study, a DTAV of 
Table I. Three-year local recurrence rate in the APR and SP groups.

\begin{tabular}{lcccc}
\hline Group & Cases, $n$ & Local recurrence, $n(\%)$ & $\chi^{2}$ & P-value \\
\hline SP & 192 & $9(4.69)$ & 0.224 \\
APR & 138 & $5(3.62)$ & - & 0.636 \\
\hline
\end{tabular}

APR, abdominoperineal resection; SP, sphincter-preserving.

Table II. Univariate analysis results of SP with associated clinicopathological features for patients with low rectal cancer.

\begin{tabular}{|c|c|c|c|c|c|}
\hline Clinicopathological features & Cases, $\mathrm{n}$ & SP group, n (\%) & APR group, n (\%) & $\chi^{2}$ & $\mathrm{P}$-value \\
\hline Gender & & & & & 0.003 \\
\hline Male & 168 & $88(52.38)$ & $80(47.62)$ & 4.733 & \\
\hline Female & 162 & $104(64.20)$ & $58(35.80)$ & & \\
\hline Age, years & & & & & 0.002 \\
\hline$\leq 40$ & 34 & $10(29.41)$ & $24(70.59)$ & 13.004 & \\
\hline $41-60$ & 134 & $81(60.45)$ & $53(39.55)$ & & \\
\hline$\geq 61$ & 162 & $101(62.34)$ & $61(37.66)$ & & \\
\hline Tumor length, cm & & & & & 0.317 \\
\hline$<4$ & 146 & $84(57.53)$ & $62(42.47)$ & 2.298 & \\
\hline $4.0-5.0$ & 132 & $82(62.12)$ & $50(37.88)$ & & \\
\hline$>5.0$ & 52 & $26(50.00)$ & $26(50.00)$ & & \\
\hline Ethnicity & & & & & 0.011 \\
\hline Han & 278 & $170(61.15)$ & $108(38.85)$ & 6.393 & \\
\hline Uyghur & 52 & $22(43.31)$ & $30(46.69)$ & & \\
\hline Growth type & & & & & 0.290 \\
\hline Ulcerative & 191 & $108(56.54)$ & $83(43.46)$ & 2.476 & \\
\hline Mass & 125 & $78(62.40)$ & $47(37.60)$ & & \\
\hline Infiltrating & 14 & $6(42.86)$ & $8(57.14)$ & & \\
\hline Tumor grade & & & & & $<0.001$ \\
\hline Well & 38 & $25(65.79)$ & $13(34.21)$ & 16.198 & \\
\hline Moderate & 182 & $120(65.93)$ & $62(34.07)$ & & \\
\hline Poorly/anaplastic & 110 & $47(42.73)$ & $63(57.27)$ & & \\
\hline Lymphatic metastasis & & & & & 0.458 \\
\hline N0 & 204 & $124(60.78)$ & $80(39.22)$ & 1.560 & \\
\hline N1 & 81 & $43(55.56)$ & $38(44.44)$ & & \\
\hline N2 & 45 & $25(51.85)$ & $20(48.15)$ & & \\
\hline Depth of invasion & & & & & 0.001 \\
\hline $\mathrm{T} 1 / \mathrm{T} 2$ & 84 & $59(70.24)$ & $25(29.76)$ & 14.645 & \\
\hline $\mathrm{T} 3$ & 126 & $79(62.70)$ & $47(37.30)$ & & \\
\hline $\mathrm{T} 4$ & 120 & $54(45.00)$ & $66(55.00)$ & & \\
\hline DTAV, cm & & & & & $<0.001$ \\
\hline $3-<5$ & 124 & $11(8.87)$ & $113(91.13)$ & 198.518 & \\
\hline $5-7$ & 206 & $181(87.86)$ & $25(12.14)$ & & \\
\hline Total infiltrated circumference (cycle) & & & & & $<0.001$ \\
\hline$<1 / 2$ & 115 & $80(69.57)$ & $35(30.43)$ & 17.878 & \\
\hline $1 / 2-<3 / 4$ & 124 & $75(60.48)$ & $49(39.52)$ & & \\
\hline$\geq 3 / 4$ & 91 & $37(40.66)$ & $54(59.34)$ & & \\
\hline Preoperative CEA, $\mu \mathrm{g}$ & & & & & 0.891 \\
\hline$<5$ & 219 & $128(58.45)$ & $91(41.55)$ & 0.019 & \\
\hline$\geq 5$ & 111 & $64(57.66)$ & $47(42.34)$ & & \\
\hline
\end{tabular}


Table II. Continued.

\begin{tabular}{|c|c|c|c|c|c|}
\hline Clinicopathological features & Cases, $\mathrm{n}$ & SP group, n (\%) & APR group, $\mathrm{n}(\%)$ & $\chi^{2}$ & P-value \\
\hline Venous tumor embolus & & & & & 0.746 \\
\hline No & 317 & $185(58.35)$ & $132(41.65)$ & 0.105 & \\
\hline Yes & 13 & $7(53.84)$ & $6(46.16)$ & & \\
\hline \multicolumn{6}{|l|}{ Diabetes history } \\
\hline No & 286 & $167(58.39)$ & $119(41.61)$ & 0.039 & 0.844 \\
\hline Yes & 44 & $25(56.82)$ & $19(43.18)$ & & \\
\hline \multicolumn{6}{|l|}{ BMI } \\
\hline$<25$ & 181 & $115(63.54)$ & $66(36.46)$ & 4.723 & 0.030 \\
\hline$\geq 25$ & 149 & $77(51.68)$ & $72(48.32)$ & & \\
\hline Tumor family history & & & & & 0.727 \\
\hline No & 266 & $156(58.25)$ & $110(41.75)$ & 0.122 & \\
\hline Yes & 64 & $36(56.25)$ & $28(43.75)$ & & \\
\hline
\end{tabular}

APR, abdominoperineal resection; SP, sphincter-preserving; DTAV, distance of the tumor from the anal verge; CEA, carcinoembryonic antigen; BMI, body mass index.

Table III. Multivariate correlation analysis of SPR surgery with associated clinicopathological features for patients with low rectal cancer.

\begin{tabular}{|c|c|c|c|c|c|c|}
\hline Variable & $\beta$-value & SE & Wald value & P-value & OR & $95 \% \mathrm{CI}$ \\
\hline DTAV & 4.714 & 0.473 & 99.526 & $<0.001$ & 111.539 & $44.176-281.625$ \\
\hline \multicolumn{7}{|c|}{ Depth of invasion ${ }^{a}$} \\
\hline $\mathrm{T} 2 \mathrm{X} 13$ & & & 11.234 & 0.004 & & \\
\hline T3 X13 (1) & 0.892 & 0.432 & 4.271 & 0.039 & 2.441 & $1.047-5.689$ \\
\hline T4 X13 (2) & 1.900 & 0.582 & 10.669 & 0.001 & 6.686 & $2.138-20.910$ \\
\hline
\end{tabular}

${ }^{a}$ Depth of invasion is an introduced dummy variable to produce the multivariate analysis. DTAV, distance of the tumor from the anal verge; SE, standard error; OR, odds ratio; CI, confidence interval; SPR, sphincter-preserving resection. X is an independent variable of the Logistic regression analysis. X13 stands for the 13th independent variate. Two dummy variables were introduced in the Logistic regression analysis. These are T3 vs. T2 and T4 vs. T2. T2 is the internal reference.

3-7 $\mathrm{cm}$ was selected, since a DTAV of $<3 \mathrm{~cm}$ can markedly decrease the effect of radical surgery. Rectal cancer with a DTAV of $>5 \mathrm{~cm}$ was shown to have a higher rate of sphincter preservation $(87.86 \%$ ) compared with cases where the DTAV was $3-5 \mathrm{~cm}(8.87 \%)$, and the difference was statistically significant $(\mathrm{P}<0.05)$. Furthermore, multivariate analysis revealed that the DTAV is an independent risk factor for treatment with SPR surgery in patients with rectal cancer.

A consensus has not been reached on whether the depth of invasion is an independent risk factor for SPR surgery in patients with low rectal cancer. However, the majority of studies $(22,29,31,32)$ support the hypothesis that the depth of invasion is an independent risk factor. The studies report that the rectum below the peritoneum has no serosa layer covered. Rectal tumors are able to infiltrate into the tissue outside the rectum and pelvis, which increases the difficulty of SPR surgery and increases the local recurrence rate $(33,34)$. In the present study, univariate and multivariate analyses indicated that the rate of sphincter preservation was associ- ated with the depth of invasion, and statistically significant differences were observed $(\mathrm{P}<0.05)$. Thus, the deeper the rectal tumor infiltrate, the lower the rate of sphincter preservation. Furthermore, univariate analysis results revealed that the sphincter-preserving factor was strongly associated with the total infiltrated circumference, which was similar to the results of a study by Cong (22). According to the growth characteristics of the malignant tumor, the longer the growth cycle and the wider the tumor infiltrates, the more difficult the surgery becomes. When rectal cancer infiltration reaches close to a complete cycle of the rectum, the depth of invasion is primarily in the T3 or T4 stage, and the adjacent tissue of the intestinal tube may be infiltrated. Consequently, SPR surgery becomes too difficult to be implemented.

Xinjiang Uygur Autonomous Region in the northwest of China comprises numerous ethnic groups that have different diets, living habits and plateau environments. Therefore, ethnicity was an important research parameter in the current study. However, the results of the present study demonstrated 
that SPR surgery success was not associated with ethnicity. Liu et al (35) reported that the rates of obesity in the Kazak and Uygur ethnic populations were 40.1 and $28.9 \%$, respectively, which were markedly higher compared with the Han ethnicity (18.4\%). The increase in surgical difficulty as a result of obesity may decrease the rate of sphincter preservation in patients from the Uygur ethnicity $(36,37)$. Furthermore, on an economical and cognitive level, rectal cancer in Uygur populations is generally diagnosed much later in the disease stage, resulting in a larger tumor size and deeper invasion, which greatly influences the rate of sphincter preservation (38-40). In the present study, univariate analysis demonstrated that the sphincter-preserving factor was significantly associated with gender, BMI, age and tumor grade. The reasons for this may be as follows: i) The male pelvis is narrower and smaller, which increases the difficulty of the surgery for patients with rectal cancer; ii) young patients tend to be diagnosed at a later stage of the disease; thus, there is more extensive invasion of adjacent tissue; iii) obesity increases the surgical difficulty, particularly with regard to sphincter preservation; and iv) a low differentiated rectal tumor may lead to deeper tumor invasion $(41,42)$.

In conclusion, there are numerous risk factors with regard to sphincter preservation for patients with low rectal cancer. The sphincter-preserving factor was demonstrated to be associated with certain clinicopathological features, including DTAV and the depth of invasion. Therefore, careful preoperative evaluation of the associated risk factors may be beneficial for selecting the precise surgical pattern (SPR or APR) and ensuring an accurate surgical procedure, which may subsequently enhance the rate of sphincter preservation and improve the quality of life of patients with low rectal cancer.

\section{Acknowledgements}

The authors thank the patients for their participation in the study. The study was supported by grants from the National $11^{\text {th }}$ Five-Year Science \& Technology Support Program of China (no. 2006BAI02A06) and the Science \& Technology Innovation Fund of Xinjiang Medical University (no. XJC201267).

\section{References}

1. Wu ZD and Wu JH (eds): Surgery. 7th edition. People's Medical Publishing House, Beijing, China, p492, 2008.

2. Mauvais F, Sabbagh C, Brehant O, et al: The current abdominoperineal resection: oncological problems and surgical modifications for low rectal cancer. J Visc Surg 148: e85-e93, 2011.

3. Rullier E, Denost Q, Vendrely V, Rullier A and Laurent C: Low rectal cancer: classification and standardization of surgery. Dis Colon Rectum 56: 560-567, 2013.

4. Richardson DP, Porter GA and Johnson PM: Population-based use of sphincter-preserving surgery in patients with rectal cancer: is there room for improvement? Dis Colon Rectum 56: 704-710, 2013.

5. Huh JW, Jung EJ, Park YA, et al: Sphincter-preserving operations following preoperative chemoradiation: an alternative to abdominoperineal resection for lower rectal cancer? World J Surg 32: 1116-1123, 2008

6. Mir SA, Chowdri NA, Parray FQ, et al: Sphincter-saving surgeries for rectal cancer: A single center study from Kashmir. South Asian J Cancer 2: 227-231, 2013.

7. Chen WQ, Zheng RS, Zhang SW, Zeng HM and Zou XN: The incidences and mortalities of major cancers in China, 2010 Chin J Cancer 33: 402-405, 2014.
8. Lopez-Kostner F, Lavery IC, Hool GR, Rybicki LA and Fazio VW: Total mesorectal excision is not necessary for cancers of the upper rectum. Surgery 124: 612-617, 1998.

9. Heald RJ, Moran BJ, Ryall RD, Sexton R and MacFarlane JK: Rectal cancer: the Basingstoke experience of total mesorectal excision, 1978-1997. Arch Surg 133: 894-899, 1998.

10. Siani LM, Ferranti F, Benedetti M, et al: Laparoscopic versus open total mesorectal excision for stage I-III mid and low rectal cancer: a retrospective 5 years analysis. G Chir 33: 404-408, 2012.

11. American Joint Committee on Cancer (AJCC): TNM staging of colorectal cancer. 7th edition. Springer, New York, USA, pp 173-206, 2010.

12. Atallah S, Albert M, DeBeche-Adams T, Nassif G, Polavarapu H and Larach S: Transanal minimally invasive surgery for total mesorectal excision (TAMIS-TME): a stepwise description of the surgical technique with video demonstration. Tech Coloproctol 17: 321-325, 2013.

13. Ministry of Health of the People's Republic of China: Chinese Standard for The Management of Colorectal Cancer. 2010 edition. Beijing, China, pp 23-24 (In Chinese).

14. Heald RJ, Husband EM and Ryall RD: The mesorectum in rectal cancer surgery-the clue to pelvic recurrence? Br J Surg 69: 613-616, 1982.

15. Maurer CA, Renzulli P, Kull C, et al: The impact of the introduction of total mesorectal excision on local recurrence rate and survival in rectal cancer: long-term results. Ann Surg Oncol 18: 1899-1906, 2011.

16. Anderin C, Granath F, Martling A, et al: Local recurrence after prone vs supine abdominoperineal excision for low rectal cancer. Colorectal Dis 15: 812-815, 2013.

17. Peeters KC, Tollenaar RA, Marijnen CA, et al: Risk factors for anastomotic failure after total mesorectal excision of rectal cancer. Br J Surg 92: 211-216, 2005.

18. You YN, Baxter NN, Stewart A, et al: Is the increasing rate of local excision for stage I rectal cancer in the United States justified?: a nationwide cohort study from the National Cancer Database. Ann Surg 245: 726-733, 2007.

19. Sun HY and Wang KK: Application experience of total mesorectum resection. Chin J Gen Pract 7: 1075-1076, 2009.

20. Nash GM, Weiss A, Dasgupta R, Gonen M, Guillem JG and Wong WD: Close distal margin and rectal cancer recurrence after sphincter-preserving rectal resection. Dis Colon Rectum 53: 1365-1373, 2010

21. Kim JC, Yu CS, Lim SB, Kim CW, Kim JH and Kim TW: Abdominoperineal resection and low anterior resection: comparison of long-term oncologic outcome in matched patients with lower rectal cancer. Int J Colorectal Dis 28: 493-501, 2013

22. Cong ZJ, Hu LH, Xing JJ, Zhang W, Fu CG, Yu ED and Zhong M: Risk factors associated with sphincter-preserving resection in patients with low rectal cancer. Int Surg 99: 330-337, 2014.

23. Martin ST, Heneghan HM and Winter DC: Systematic review of outcomes after intersphincteric resection for low rectal cancer. Br J Surg 99: 603-612, 2012.

24. Keum MA, Lim SB, Kim SA, et al: Clinicopathologic factors affecting recurrence after curative surgery for stage I colorectal cancer. J Korean Soc Coloproctol 28: 49-55, 2012.

25. Du JY and Zhang Y: Clinical analysis of 45 cases receiving sphincter-preserving operation of low rectal cancer. Chongqing Yi Yao 39: 589-590, 2010 (In Chinese).

26. Williams NS, Dixon MF and Johnston D: Reappraisal of the 5 centimetre rule of distal excision for carcinoma of the rectum: a study of distal intramural spread and of patients' survival. Br J Surg 70: 150-154, 1983.

27. Seo SI, Yu CS, Kim GS, et al: Characteristics and risk factors associated with permanent stomas after sphincter-saving resection for rectal cancer. World J Surg 37: 2490-2496, 2013.

28. Açar Hİ and Kuzu MA: Perineal and pelvic anatomy of extralevator abdominoperineal excision for rectal cancer: cadaveric dissection. Dis Colon Rectum 54: 1179-1183, 2011.

29. Temple LK, Romanus D, Niland J, Veer AT, Weiser MR, Skibber J, Wilson J, Raiput A, Benson A, Wong YN and Schrag D: Factors associated with sphincter-preserving surgery for rectal cancer at national comprehensive cancer network centers. Ann Surg 250: 260-267, 2009

30. Bordeianou L, Maguire LH, Alavi K, et al: Sphincter-sparing surgery in patients with low-lying rectal cancer: techniques, oncologic outcomes, and functional results. J Gastrointest Surg 18: 1358-1372, 2014. 
31. Orsenigo E, Di Palo S, Vignali A and Staudacher C: Laparoscopic intersphincteric resection for low rectal cancer. Surg Oncol 16 (Suppl 1): S117-S120, 2007.

32. Chuwa EW and Seow-Choen F: Outcomes for abdominoperineal resections are not worse than those of anterior resections. Dis Colon Rectum 49: 41-49, 2006.

33. Bugg WG, Andreou AK, Biswas D, et al: The prognostic significance of MRI-detected extramural venous invasion in rectal carcinoma. Clin Radiol 69: 619-623, 2014.

34. Bhangu A, Fitzgerald JE, Slesser A, et al: Prognostic significance of extramural vascular invasion in T4 rectal cancer. Colorectal Dis 15: e665-e671, 2013.

35. Liu C, Ma X, Ma YT, et al: Prevalence on overweight and obesity in Han, Uygur and Hazakh in adults from Xinjiang. Zhonghua Liu Xing Bing Xue Za Zhi 31: 1139-1143, 2010 (In Chinese).

36. Chern $\mathrm{H}$, Chou J, Donkor C, et al: Effects of obesity in rectal cancer surgery. J Am Coll Surg 211: 55-60, 2010.

37. Aytac E, Lavery IC, Kalady MF and Kiran RP: Impact of obesity on operation performed, complications and long-term outcomes in terms of restoration of intestinal continuity for patients with mid and low rectal cancer. Dis Colon Rectum 56: 689-697, 2013.
38. Liu HM, Li XJ, Wang L, et al: Analysis of clinic pathological characteristics and prognosis between Uyghur and Han people with rectal cancer. Chongqing Yi Xue 44: 478-481, 2015.

39. Sun ZQ, Wang HJ, Zhao ZL, et al: Significance of HPV Infection and Genic Mutation of APC and K-ras in Patients with Rectal Cancer. Asian Pacific J Cancer Prev 14: 121-126, 2013.

40. Yusup A, Wang HJ, Rahmutula A, et al: Clinical features and prognosis in colorectal cancer patients with different ethnicities in Northwest China. World J Gastroenterol 19: 7183-7188, 2013.

41. Chen ZH, Song XM, Chen SC, et al: Risk factors for adverse outcome in low rectal cancer. World J Gastroenterol 18: 64-69, 2012.

42. Li SY, Yu B, Liang ZJ, et al: Clinical study of 102 cases of abdominal-anus resection with telescopic anastomosis of colon rectal mucosa for lower segment of rectal cancer. Zhonghua Wai Ke Za Zhi 41: 812-814, 2003 (In Chinese). 